\title{
Impact Of Multiple Antigenic Epitopes From ApoB100, HHSP60 And Chlamydophila \\ Pneumoniae (Cpn) On Atherosclerotic Lesion Development In $\mathrm{Apob}^{\mathrm{tm} 2 \mathrm{Sgy}} \mathrm{Ldll}^{\mathrm{tm} 1 \mathrm{Her}} \mathrm{J}$ Ince
}

Xinjie $\mathrm{Lu}^{1 *}$, Min Xia ${ }^{1}$, Valeria Endresz ${ }^{2}$, Ildiko Faludi ${ }^{2}$, Eva Gonczol ${ }^{3}$, Lakshmi Mundkur ${ }^{4}$, Daxin Chen $^{1,4}$, and Vijay Kakkar ${ }^{1,5^{*}} \curvearrowright$

${ }^{1}$ The Mary and Garry Weston Molecular Immunology Laboratory, Thrombosis Research Institute, London, United Kingdom; ${ }^{2}$ Department of Medical Microbiology and Immunobiology, University of Szeged, Szeged, Hungary; ${ }^{3}$ Virology, National Center for Epidemiology, Budapest, Hungary; ${ }^{4} \mathrm{MRC}$ Centre for Transplantation, King's College London. ${ }^{5}$ Thrombosis Research Institute, Bangalore, India;

*Corresponding authors: Xinjie Lu and Vijay Kakkar, Thrombosis Research Institute, London, SW3 6LR Email: xlu@tri-london.ac.uk, vijay@ tri-london.ac.uk

Tel: 0044(0)2073518312; Fax: 0044(0)2073518324 


\begin{abstract}
Aims: To assess whether immunizing $A p o b^{\text {tm2Sgy }} \operatorname{Ldlr}^{\mathrm{tm} 1 \mathrm{Her}} \mathrm{J}$ mice simultaneously with different atherosclerosis-related epitopes engineered in a single recombinant protein is effective in reducing atherosclerotic lesions.
\end{abstract}

Methods and results: Antigenic epitopes were incorporated into a dendroaspin scaffold: AHC (ApoB100 peptide + hHSP60 peptide [hHSP60 $\left.{ }_{153-163}\right]+$ putative epitope derived from Chlamydophila

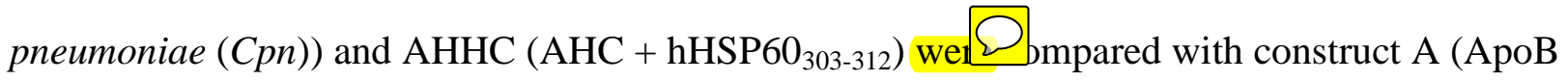
peptide), construct H (hHSP60 ${ }_{153-163}$ ), and construct AH (ApoB100 peptide + hHSP60 $_{153-163}$ ). Immunization with 2 multiple-antigenic epitope constructs elicited high levels of antibodies against each epitope (apart from hHSP60 ${ }_{153-163}$, which induced a low antibody response) in ApoB100 only, $\mathrm{LDLr}^{-/-}$mice. Histological analyses demonstrated that the mice immunized with AHHC and AHC showe $\Omega$ gnificantly greater reductions in atherosclerotic lesions compared with controls $(64.2 \%$ and $63.1 \% ; P<0.001$, respectively) an $\bigcirc$ mpared with constructs A $(24.5 \% ; P<0.05), \mathrm{H}(27.2 \%$; $P=0.013)$ and $\mathrm{AH}(42.9 \% ; P<0.001)$. Moreover, combination of 2 short $C p n$ peptides along with ApoB and hHSP60 peptides had an additive effect on reducing the lesion without Cpn infection. Reduction in plaque size correlated with cellular infiltration, and cytokine/chemokine secretion in serum or by stimulated spleen cells as well as specific cellular immune responses when compared with controls.

Conclusions: Immunization of mice with a single construct containing multiple epitopes derived from ApoB100, hHSP60 and Cpn was more effective in reducing early atherosclerotic lesions through the induction of a specifc Treg cell response than was the construct containing either mono- or bi- 
epitopes. This approach offers attractive opportunities for the design of protein-based, multivalent vaccines against atherosclerosis.

Key words: immunization, ApoB-100, hHSP60, C. pneumoniae and atherosclerosis. 


\section{Introduction}

Atherosclerosis is increasingly recognized as a complex chronic inflammatory disease of the arterial walls [1-3], as evidenced by the presence of inflammatory cells, activated immune cells, and cytokines in lesions, all of which indicate involvement of the immune system [4]. Atherosclerotic plaques are known to contain macrophage-derived foam cells in which macrophages interact with T-cells to produce a wide array of cytokines that can exert both proand anti-inflammatory effects [5].

Macrophages interact with T-cells to produce a wide array of cytokines that can exert both pro- and anti-inflammatory effects [6]. Antibodies against aldehyde-modified ApoB100, a major constituent of low density lipoprotein, reduce atherosclerosis in mice expressing human ApoB100, suggesting both antigenic and immunogen 1 ples of ApoB100 [7]. Antibodies against epitopes of the human heat shock protein 60 (hHSP60) molecule (hHSP60 ${ }_{153-163}$ : AELKKQSKPVT and hHSP60 $303-312$ : PGFGDNRKNQ) are present in atherosclerotic patients and share considerable homology with human cytomegalovirus (HCMV)-derived protein (immediate early protein UL122) and Porphyromonas gingivalis microbial HSP60. Sequence homology between microbial HSP60 and hHSP60 has been suggested to result in immunological cross-reactivity, which may play a role in atherogenesis $[8,9]$. Titers of Cpn antibodies are not always positively associated with the Cpn organism in atheroma; however, these antibodies might exert cross-reactivity to non-Cpn antigens (10). In addition, chlamydial antigens are involved in cell-mediated immune responses; antigenic epitopes derived from the Cpn proteins, including the major outer membrane protein (MOMP) (residues 67-74:

GDYVFDRI), and from the putative outer membrane protein 5 (residues: 283-291: QAVANGGAI) of Cpn are thought to elicit cytotoxic T lymphocyte response following peptide immunization [1 
Intranasal administration of recombinant MOMP was found to promote anti-atherogenic T-cell responses and halt the development and progression of atherosclerotic plaques in $\mathrm{ApoE}^{-/-}$mice [ $Q D$ However, much less is known about the effect of these antigenic epitopes on atherosclerotic lesions without Cpn infection.

The use of recombinant antigens where antigen delivery is dependent upon epitopes of the protein scaffold is likely to prove effective due to the natural variability in loop length and conformation, and varying $\alpha$-helical and $\beta$-sheet content. Recombinant antigens of this type have indeed induced protective immune responses in animal models [13]. We have used a protein scaffold-dendroaspin, a short-chain neurotoxin homologue from the venom of Elapidae snakes, with no detectable neurotoxicity. Its core structure is similar to that of short-chain neurotoxins, but with a novel arrangement of loops [14] that makes it a unique protein scaffold for engineering a recombinant antigen.

We have recently demonstrated that simultaneous immunization of $A p o b^{\mathrm{tm} 2 \mathrm{Sgy}} \mathrm{Ldlr}{ }^{\mathrm{tm} 1 \mathrm{Her}} \mathrm{J}$ mice with KLH-conjugated ApoB peptide (residues 688-707, numbered including signal peptide) and hHSP60 peptide (residues 153-163) significantly reduced atherosclerotic lesion development [1]. In the present study we sought to incorporate the epitopes derived from ApoB100, hHSP60 and Cpn into a dendroaspin scaffold to generate multiple antigenic molecules and to investigate whether these constructs enhance lesion reduction without infecting the mice with Cpn.

\section{Methods}




\subsection{Expression and purification of recombinant glutathione S-transferase constructs}

Glutathione S-transferase (GST)-dendroaspin (Figure S1A) and GST-recombinant construct A (ApoB100-peptide, amino acid (AA) 688-707, numbered including signal peptide), construct $\mathrm{H}$ (hHSP60 153-163); construct AH (ApoB100-peptide + hHSP60 153-163); construct AHC (ApoB100peptide + hHSP60 $_{153-163}+$ a combination of MOMP AA 66-73 and outer membrane 5, AA 283-291 of Cpn [designated as Cpn peptide]) and construct AHHC (ApoB100-peptide + hHSP60 $_{153-163}+$ hHSP60 $0_{303-312}+C p n$ peptide) (Figure $S 1 B$ ) were generated. These recombinant molecules were expressed in Escherichia coli (BL-21 strain), purified by affinity and ion exchange chromatography and analyzed by sodium dodecyl sulfate polyacrylamide gel electrophoresis (Figure SIC).

\subsection{Animal experiments}

The experiments were approved by the Animal Welfare Committee of the University of Szeged and conform with the Directive 2010/63/EU of the European Parliament.

$\mathrm{Apob}^{\mathrm{tm} 2 \mathrm{Sgy}} \mathrm{Ldlr}^{\mathrm{tm} 1 \mathrm{Her}} \mathrm{J}$ mice were used in our study in a total of 8 groups (5 sample groups, 3 control groups) consisting of 5-6 week-old males (similar body weight, $19.2 \pm 2 \mathrm{~g}$; Table S1) in each group, two separate experiments were performed with a total of 8 mice.

The immunizing antigens used were construct $\mathrm{A}, \mathrm{H}, \mathrm{AH}, \mathrm{AHC}$ and AHHC. Alum was used as an adjuvant. The repetitive immunization multiple sites strategy (RIMMS) was adopted [1] and mice were sacrificed at the end of week 12 (a high fat diet was started at the end of week 2 and continued for 10 weeks). The 3 control groups followed the diet programme after injections with GSTdendroaspin plus Alun $\bigcirc$ hd PBS, respectively. 


\subsection{Tissue preparation and antibody response measurements}

Twelve weeks after the first immunization, tissues were harvested and mounted in OCT and in paraffin, for immunohistochemical analyses and lesion measurement, respectively. Atherosclerosis in aortic roots was examined by Image-Pro Plus TM software, version 4.0 (Media Cybernetics, Inc.,

Bethesda, MD, USA). The peptide-specific antibody levels in the plasma samples were measured by ELISA following the manufacturer's instructions.

\subsection{Immunohistochemical and morphometric analyses, quantitative measurements of atherosclerosis and immunohistochemical analysis of forkhead box protein 3 (Foxp3) expression in CDSPlenocytes}

OCT-embedded samples were used for immunohistochemical analyses. Sections of paraffin-embedded tissues were stained with hematoxylin and eosin (HE) and elastin/van Gieson (Sigma) for histological examination and were evaluated using an Olympus U-ULH Optical microscope (Olympus Optical Co. Ltd, Tokyo, Japan).

\subsection{Flow cytometric analysis of Foxp3 expression in $\mathrm{CD}$ cells in lymph nodes}

Cells from lymph nodes were processed for staining (30 minutes at $4^{\circ} \mathrm{C}$ ) using allophycocyaninanti-mouse Foxp3 antibody (BioLegend, Cambridge, UK). Cells were analyzed with a BeckmanCoulter FC-500 Analyzer (Bachman Coulter, High Wycombe, UK). 


\subsection{Measurement of cytokines}

IL-10 and TNF- $\alpha$ levels in the lesions were quantified by immunohistochemical analyses (rat antimouse TNF- $\alpha$ and IL-10 purchased from BioLegend, CA, USA). Levels of ConA-induced IL-10, TGF- $\beta$, TNF- $\alpha$ and IFN- $\gamma$ in splenocyte cultures were measured. Plasma levels of the cytokines interleukin (IL)-10, transforming growth factor (TGF)- $\beta$, tumor necrosis factor (TNF)- $\alpha$ and interferon (IFN)- $\gamma$ were also measured by ELISA following the manufacturer's instructions (R\&D systems, Abingdon, UK).

\section{Antigen-specific regulatory function assays}

Antigen-specific regulatory function assay experiments were performed as previously described by Herbin et al [15] and Klingenberg et al [16] with some modifications. CD ${ }^{+} \mathrm{CD} 25^{+}$Treg cells were isolated from the spleen $\mathrm{CD} 4^{+} \mathrm{T}$-cells of $\mathrm{Apob}^{\mathrm{tm} 2 \mathrm{Sgy}} \mathrm{Ldll}^{\mathrm{tm} 1 \mathrm{Her}} \mathrm{J}$ mice immunized subcutaneously with construct AHC. T-effector cells $\left(\mathrm{CD} 4^{+} \mathrm{CD} 25^{-}\right.$cells) were isolated from the spleen of mice immunized with construct AHHC. Co-cultured $\mathrm{CD} 4^{+} \mathrm{CD} 25^{-}$cells with $\mathrm{CD} 4^{+} \mathrm{CD} 25^{+}$cells in the presence of $2 \times 10^{4}$ APC (3000 rad irradiated splenocytes) per well were stimulated with $1 \mu \mathrm{M}$ of either construct A or $\mathrm{H}$ or with PBS control measured by proliferation assay.

\subsection{Statistical analyses}

Data are reported as mean \pm standard error of the mean $( \pm$ SEM $)$, unless otherwise indicated.

Figures were plotted using graph-pad Prism 5.01 and Sigma plot 9.0. For atherosclerotic lesion size, data were compared and intergroup differences were conducted using one-way ANOVA for

multiple comparisons and post hoc bonferroni test. Oth 2 data were analyzed using Student's $t$ test (2-tailed analyses). Non-parametric distributions were analysized using Mann-Whitney $U$ 
test for pairwise comparisons and the Kruskal-Wallis test for multiple comparisons. Differences between groups were considered significant at $\mathrm{P}$ values below 0.05 .

An extended description of the methods is available as an online supplement.

\section{Results}

\subsection{Peptide-specific immunoglobulin $G$ in the sera of immunized mice}

Antibody levels were measured by the ELISA test in mice immunized with either dendroaspin (GST tagged) or constructs (GST-tagged) at weeks 2 and 12. Construct A-induced ApoB peptide-specific antibody was observed when ApoB peptide was used as an ELISA antigen (Figure 1A); construct AHinduced ApoB-specific antibodies were also detected (Figure $1 C$ ). Constructs $\mathrm{H}$ and $\mathrm{AH}$ did not induce detectable levels of the hHSP60 ${ }_{153-163}$-specific $\operatorname{IgG}$ (Figures $1 B$ and $1 C$ ); neither did constructs AHC and AHHC which contain hHSP60 $0_{153-163}$ peptide 1 (Figures $1 D$ and $1 E$ ). IgG against hHSP60 $303-$ 312 was detectable in AHHC-immunized animals.

High antibody levels against Cpn peptide were detected in mice immunized with constructs AHC or AHHC at weeks 2 and 12 (Figures $1 D$ and $1 E$ ). The GST-dendroaspin control-immunized mice showed very low levels of antibody responses against any peptide antigen (Figure 1).

\subsection{Reduction of atherosclerotic lesion size in the aortic sinus}

Following immunization with constructs $\mathrm{A}, \mathrm{H}, \mathrm{AH}, \mathrm{AHC}$, and $\mathrm{AHHC}$ and after a 10-week high-fat diet, the aortic sinuses of the mice were evaluated for the extent of atherosclerosis. The calculated plaque sizes from the immunized animals were compared with those of the controls. Representative sections from experimental groups are shown in Figure 2A. Lesion size was similar in thre ntrol 
mice immunized with adjuvant (Alum) only $(31.5 \pm 2 \%)$, GST-dendroaspin + Alum $(32.0 \pm 1.9 \%)$ or PBS $(29.1 \pm 2 \%)$ (Figure S3). As three control groups of mice showed a similar lesion size, GSTdendroaspin was taken as a representative control hereafter. Valvular plaque areas and the ratio of plaque areas in $\mu \mathrm{m}^{2}$ versus total areas are shown in Figures $2 B$ and $2 C$, respectively. Lesion size was significantly smaller in mice immunized with either construct A $(P=0.018)$ or $\mathrm{H}(P=0.013)$ compared with controls $(32.0 \pm 2.0 \%)$, and significantly reduced lesion areas were observed in mice immunized with construct AH $(18.3 \pm 1.9 \%)$, compared with mice immunized with construct A $(P=0.018)$, but not in the case of construct $\mathrm{H}(P=0.076)$ (Figure $2 C)$. However, there was no significant difference in lesion size between mice immunized with construct A $(24.2 \pm 0.86 \%)$ or $\mathrm{H}(23.3 \pm 1.85 \% ; P=0.704)$. The smallest lesion area was observed in mice immunized with either construct AHHC (11.46 \pm $0.79 \%)$ or construct AHC $(11.81 \pm 0.70 \%)$; this difference was significant $(P<0.001)$ when compared with controls as well as with the other constructs (Figure 2C). Reduction in lesion size was expressed as a percentage of decrease in the lesion size in the aortic sinus compared with lesions in the control mice: $24.5 \%$ following immunization with construct A and $27.2 \%$ with construct $\mathrm{H}$ (Figure 2D). Mice immunized with construct AH showed significant reductions in lesion size (42.9\%), and immunization with constructs $\mathrm{AHC}$ and $\mathrm{AHHC}$ resulted in greater reductions than with construct $\mathrm{AH}(63.1 \%$ and $64.2 \%$, respectively versus $42.9 \%$ ) (Figure $2 D$ ).

\subsection{Amount of inflammatory cells and $\mathrm{CD4}^{+}$cells expressing Foxp3 in local (in the lesions of aortas) and remote organs: splenocytes and lymphocytes

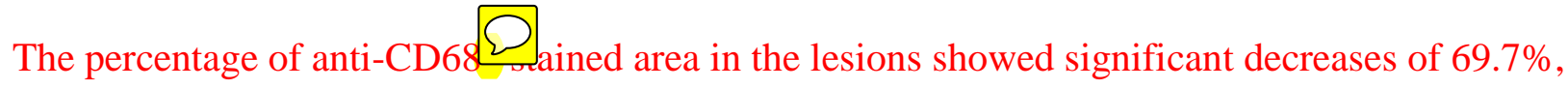 $68.8 \%, 66.3 \%, 47.0 \%$, and $41.0 \%$ in mice immunized with constructs AHHC $(P<0.001)$,}


AHC $(P<0.001)$, AH $(P=0.003), \mathrm{A}($ all $P=0.005)$ and $\mathrm{H}(P=0.021)$, respectively (Figures $3 A$ and $3 D)$; the anti-CD68 ${ }^{+}$-stained area in lesions in control mice (19.5\%) was set as at 100\% (0\% reduction).

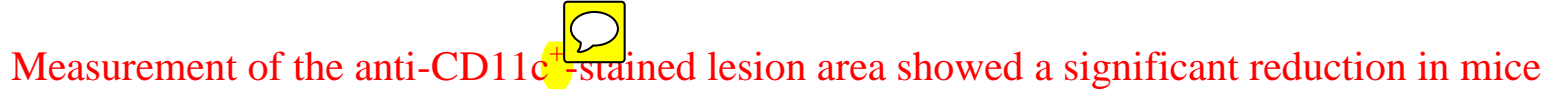
immunized with all of recombinant antigens with reductions of $72.6 \%, 67.8 \%, 62.5 \%, 40.3 \%$, and $50.2 \%$ for immunization with constructs $\mathrm{AHHC}, \mathrm{AHC}, \mathrm{AH}, \mathrm{A}$, and $\mathrm{H}$, respectively (Figures $3 \mathrm{~B}$ and $3 C$ ), compared with the $\mathrm{CD} 11 \mathrm{c}^{+}$content of the lesions in the control group. Double immunostaining for CD68 and CD11c clearly revealed that most of macrophages were $\mathrm{CD} 68^{+} \mathrm{CD} 11 \mathrm{c}^{+}$, indicating the myeloid origin of this cell type in lesions (Figures $3 A-3 D$ ) [17].

The proportion of $\mathrm{CD}^{+}$cells expressing Foxp3 was approximately 9-, 7-, and 4-fold higher (19.1\%, $P<0.001 ; 13.5 \%, P<0.001 ; 8.2 \%, P<0.001)$ in mice immunized with constructs AHHC, AHC and AH, respectively, compared with controls (2.0\%) (Figures $3 D$ and $3 E$ ), whereas the proportion of CD4 ${ }^{+}$ cells expressing Foxp3 was approximately 2.5 -fold higher (5.0\% versus $2.0 \%, P=0.002 ; 5.2 \%$ versus 2.0\%, $P=0.012$, respectively) in construct A- and H-immunized mice (Figures 3D-F).

\section{With the exception of $\mathrm{AH}$, which did not show a significant increase of Foxp3 expression when} compared with construct $\mathrm{A}(P=0.240)$ and $\mathrm{H}(P=0.114)$ (Figures $3 H-I)$, significantly higher levels of Foxp3 expression were observed in spleen $\mathrm{CD}^{+}$cells from mice immunized with the multi-epitope constructs AHHC $(20.4 \pm 0.9 \%)$, AHC $(20.3 \pm 1.3 \%)$, and AH $(18.8 \pm 1.9 \%)$, when compared with those of single-epitope constructs A $(15.4 \pm 0.9 \%)$ and $\mathrm{H}(15.3 \pm 0.7 \%)$. In addition, expression of Foxp3 in spleen $\mathrm{CD}^{+}$cells from mice immunized with the recombinant antigen constructs was significantly higher $(P<0.001)$ than that in controls immunized with GST-dendroaspin (Figures 3H-I). 
Similarly, mice immunized with the recombinant antigens showed significantly increased Foxp3 expression in lymph node $\mathrm{CD} 4^{+}$cells immunized with GST-dendroaspin (Figure $3 \mathrm{~J}, P<0.001$ ).

Significantly increased foxp 3 pxession levels in mice immunized with tri- or quadri-eptiope antigens AHC and AHHC were also observed when compared with those immunized with the mono-epitope antigen $\mathrm{A}$ or $\mathrm{H}$ (Figure $3 J, P<0.05)$.

The results of statistical analysis showed that the increased levels of Foxp3 contents either in the lesion or in spleen $\mathrm{CD} 4^{+}$cells as well as lymph node $\mathrm{CD} 4^{+}$cells correlated with a decreased percentage of lesion-occupied area in aorta sinus (Figures $S 4 F-H$, correlation $\alpha=0.05, P<0.05-0.001$ ).

\subsection{Expression of anti-inflammatory cytokines and pro-inflammatory cytokines in lesion sites and levels of cytokines in plasma and in the supernatants of stimulated splenocytes}

IL-10 expression in the aortic lesions of mice immunized with constructs $\mathrm{A}, \mathrm{H}, \mathrm{AH}, \mathrm{AHC}$ and $\mathrm{AHHC}$ detected by immunohistochemistry is shown in Figure $4 A$. The proportion of $\mathrm{CD}^{+}{ }^{+}$cell $\Omega_{\text {pressing }}$ IL-10 was significantly higher in mice immunized with construct AH ( 14-fold; $11.9 \%$ versus $0.8 \%$; $P<0.001)$, A ( $\sim 8$-fold; $7.2 \%$ versus $0.8 \% ; P<0.001)$, and $\mathrm{H}(\sim 8$-fold; $6.7 \%$ versus $0.8 \% ; P<0.001)$, compared with that in controls. The proportion of $\mathrm{CD} 4^{+}$cells expressing IL-10 was $>24$-fold higher $(P<0.001)$ in mice immunized with either construct AHC or AHHC, showing $19.2 \%$ and $21.0 \%$, respectively, compared with controls at $0.8 \%$ (Figure $4 B$ ).

Immunohistochemical analyses of TNF- $\alpha$ showed significantly smaller TNF- $\alpha$ occupied areas in lesions of mice immunized with constructs compared with controls $(9.0 \pm 1.1 \%$ for $\mathrm{A} ; 9.9 \pm 1.0 \%$ for $\mathrm{H}, 6.0 \pm 0.5 \%$ for $\mathrm{AH}, 6.2 \pm 0.5 \%$ for $\mathrm{AHC}$ and $6.1 \pm 0.5 \%$ for $\mathrm{AHHC}$, and $17.3 \pm 1.4 \%$ for controls $)$ 
(Figures $4 C$ and $4 D$ ). These data represent a percent reduction of $48.1 \%, 42.8 \%, 65.4 \%, 64.2 \%$ and $64.8 \%$, respectively, compared with controls (total lesion area defined as $100 \%$, and $0 \%$ reduction). Higher degree of reduction was produced by constructs $\mathrm{AH}, \mathrm{AHC}$ and $\mathrm{AHHC}$ versus construct $\mathrm{A}$ or $\mathrm{H}$.

Plasma levels of atheroprotective cytokines IL-10 $(P<0.001$ or $P=0.001)$ and TGF- $\beta(P<0.001)$ were significantly increased in mice immunized with these constructed antigens compared with controls (Figures $4 E$ and $4 F$ ). Immunization with the single epitope constructs $\mathrm{A}$ or $\mathrm{H}$ had significantly less effect than with the bi- or multi-epitope containing constructs (AH, AHC and AHHC) on promoting the secretion of IL-10 and TGF- $\beta(P<0.05-0.001)$. Plasma levels of the atherogenic cytokine TNF- $\alpha$ were significantly reduced by immunization with constructs $\mathrm{AH}, \mathrm{AHC}$ and $\mathrm{AHHC}$ (Figures 4G). A similar trend was obtained for these constructs in respect of the plasma levels of IFN- $\gamma$ (Figures $4 H$ ). Although no statistically significant difference was found between mice immunized with construct AH and the 2 multi-epitope constructs (AHC and $\mathrm{AHHC}$ ) in plasma levels of these 2 atherogenic cytokines, a significant difference was found in mice immunized with construct AHHC versus A or $\mathrm{H}$ in plasma levels of IFN- $\gamma$ (Figures $4 G$ and $4 H, P<0.05$ ).

Supernatants of splenocytes from mice immunized with these constructs individually showed significantly increased secretion of IL-10 (Figure 4I) and TGF- $\beta$ (Figure 4J), stimulated with 10 or $100 \mu \mathrm{g} / \mathrm{mL}$ of ConA $(P<0.05-0.001)$. The incremental secretion of IL-10 in construct AHHCimmunized mice was significantly higher than in the case of the other constructs tested. In contrast, significantly decreased secretion of TNF- $\alpha$ (Figure $4 K$ ) and IFN- $\gamma$ (Figure $4 L$ ) was found in supernatants of splenocytes in mice immunized with these protein antigens. Again, a significantly 
greater decrease in the secretion of TNF- $\alpha$ was observed in mice immunized with constructs AH, AHC, and AHHC versus those in construct A-immunized mice (Figure $4 K$; $P<0.05-0.01$ ) while a significantly greater decrease in secretion of IFN- $\gamma$ was detected in constructs AH-, AHC- and AHHC-immunized mice versus construct A-or construct $\mathrm{H}$-immunized mice (Figure $4 L, P<0.05$ 0.01). Both construct AHHC- and construct AHC-immunized mice demonstrated significantly less IFN- $\gamma$ secretion than AH-immunized mice $(P<0.05)$.

The results of statistical analysis showed that the increased levels of IL-10 and TGF- $\beta$ in the plasma $Q$ supernatants of splenocytes stimulated by $\mathrm{CoA}^{\text {at }} 10 \mu \mathrm{g} / \mathrm{ml}$ as well as the IL-10 positive area colocalised with $\mathrm{CD}^{+}$in the lesion correlated correlated with a decreased percentage of lesion-occupied area in aorta sinus (Figures $S 4 A-E$, correlation $\alpha=0.05, P<0.05-0.001$ ).

\subsection{Evaluation of antigen specific regulation function}

$\mathrm{CD}^{+}$T-cells from mice immunized with the recombinant constructs were incubated with the corresponding immunizing antigens at 0 to $10 \mu \mathrm{M} / \mathrm{L}$ and a dose-dependent significant increase in proliferative response was shown between $0.1-1 \mu \mathrm{M} / \mathrm{L}$. CD4 ${ }^{+} \mathrm{T}$-cell proliferative responses were observed from antigen-immunized mice incubated with the corresponding immunizing antigen and the response was specific compared with those incubated with PBS in which the responses were smaller and non-specific (Figures S5 A-F).

To assess whether functional Treg cells were induced by immunization, we co-cultured antigen-specific Treg cells with CD4 ${ }^{+}$effector T-cells $\left(\mathrm{CD} 4^{+} \mathrm{CD} 25^{-} \mathrm{T}\right.$-cells) $\mathrm{Deffector}_{\text {-cell }}$ proliferation was suppressed in a dose-dependent manner in the presence of Treg cells from AHC-immunized mice stimulated by either construct A or H (Figure 5A) compared Treg cell 
from GST-control stimulated by either construct A or H (Figure 5B). The differences were<smiles>C1=CC=C1</smiles>

significant when adding Tregs into the effector cells at the ratios between 1:1 8:1

$(P<0.05 \sim<0.001)$ apart from stimulation by $\mathrm{H}$ at the ratio of $8: 1(P=0.06)$ compared that without addition of Tregs. No such suppression was observedrmm GST-immunized control mice (Figure $5 \mathrm{~B})$

\section{Discussion}

The effect of ApoB peptide- and HSP peptide-based immunization on atherosclerotic lesion reduction has been reported by our and other laboratories [1, 18,19]. In this study, we have investigated the effect of protein-based, multiple epitope-containing antigens on atherosclerotic lesions and established an additional effect of Cpn epitope in construct $\mathrm{AHC}$ and $\mathrm{AHHC}$ compared with construct $\mathrm{AH}$ in $\mathrm{Apob}^{\mathrm{tm} 2 \mathrm{Sgy}} \mathrm{Ldlr}^{\mathrm{tm} 1 \mathrm{Her}} \mathrm{J}$ mice.

The selection of construct AH (i.e. ApoB and hHSP60 peptides introduced into a constrained protein scaffold) was based on an extension of our previous work [1], which showed a synergistic effect of these peptide epitopes on atherosclerotic lesion reduction. This mouse strain was used because the $A p o b^{\text {tm2Sgy }} \mathrm{Ldll}^{\mathrm{tm} 1 \mathrm{Her}} \mathrm{J}$ mice show significantly high degree of atherosclerosis after being fed a high-fat diet [7]. Furthermore, our data also demonstrated that a Cpn-derived peptide attached to the Cterminus of constructs $\mathrm{AHHC}$ and $\mathrm{AHC}$ evoked a strong immune response and significantly reduced atherosclerotic lesions without $C p n$ bacterial infection. An additive effect was found with AHC containing a Cpn-derived peptide compared with that of AH without a Cpn-derived peptide. This finding suggests that Cpn-derived peptide may have a synergistic effect through the interaction with other epitopes such as ApoB peptide or hHSP60 153-163. In addition, high cross-reactivity was observed 
in the case of ApoB peptide-specific antibody with Cpn-peptide antigen, some degree of crossreactivity of $C p n$ antibody observed with ApoB peptide antigen (Figures $S 2 A$ and $S 2 B$ ), indicating that the additive effect of the Cpn epitope on lesion reduction in AHC and AHHC may be due to molecular mimicry. However, this molecular mimicry has been shown to occur in the absence of any true sequence homology between Cpn-derived peptide and ApoB peptide using computer-based software SIM-Alignment Tool for protein or peptide sequences (http://expasy.org/tools/sim-prot.html), this finding concurs with the report by Kohm et al [20]. In this case, it could explain the finding that antigenic surfaces, rather than sequence homology dictate molecular mimicry [21]. The mechanism of the effect of Cpn-derived epitope in AHC and AHHC constructs on reducing atherosclerotic lesions therefore remains under investigation at this point.

Our results suggest that immunization with ApoB-containing constructs induces an antigen-specific antibody response that is associated with an anti-atherogenic effect, detected as a significant reduction in the size of the atheromatous lesion area, while the construct containing HHSP60 $153-163$ peptide did not induce significant levels of antibody response. A specific antibody response was not observed in earlier studies using HSP60 peptides as an anti-atherosclerotic vaccine [19], wherein the mechanism of protection was reported to be mediated by regulatory T-cells. Prevention of lesion development by HSP60 epitopes is likely to be mediated by a reduction in inflammation through a regulatory T-cell response.

Immunization with construct AHHC containing a second hHSP60 epitope (hHSP60303-312) in our 10week, high-fat diet (HFD)-based Apob ${ }^{\mathrm{tm} 2 \mathrm{Sgy}} \mathrm{Ldlr}^{\mathrm{tm} 1 \mathrm{Her}} \mathrm{J}$ mouse model failed to show an added reduction in lesion area despite the antibody response and the increase in anti-atherogenic cytokines. 
Our study demonstrates that an antigen-specific humoral response and a modified cellular immune response accompany reduced lesion size. However, considering the facts that increased level of IL-10 level was found in the plasma and was produced by ConA-stimulated splenocytes of the AHHC immunized mice compared with that in AHC-immunized mice, it is reasonable to speculate that hHSP60 $0_{303-312}$ may either have an additive role or its effect is a consequence of internal interactions with other introduced epitopes. A further study to discriminate between AHC from AHHC-immunized mice fed for a longer period with a HFD is planed.

Cellular infiltration into atherosclerotic lesions results in increased levels of macrophages, activated $\mathrm{CD}^{+} \mathrm{T}$-cells and dendritic cells (markers of early lesion formation) [22]. We observed that low numbers of macrophages, $\mathrm{CD} 4^{+} \mathrm{T}-$, and $\mathrm{CD} 11 \mathrm{c}^{+}$-cells, and high numbers of Treg cells, in mice were due to immunization with constructs $\mathrm{AHHC}, \mathrm{AHC}$ and $\mathrm{AH}$. In agreement with the results of the present study, Cybulsky et al reported that cells bearing markers of DCs, including CD11c, take up residence just beneath the endothelium in the lesser curvature of mice [23]. Moreover, the results of our study show that $\mathrm{CD} 68^{+} \mathrm{CD} 11 \mathrm{c}^{+}$cells are the main macrophage subset in lesions, but their functions, and whether their function is affected by the constructs, need to be further explored [17]. Vaccination using mature DCs pulsed with oxLDL-induced, oxLDL-specific T-cells with a lowered Th1 response $\mathrm{P}$ ricreased the levels of oxLDL-specific antibodies and reduced 2 Teston size [24]. Therefore, it will be interesting in future studies to determine whether vaccination using mature DCs pulsed with these recombinant construct-induced-specific T-cells could reduce lesion size. $\curvearrowright$

The significant difference observed between the effects of immunization with bi- or multi-epitope constructs concurs with an additive effect seen in our previous study where immunization of mice with 
a combination of ApoB and hHSP60 peptides nad a significantly greater effect on early lesion formation compared with the use of each peptide individually [1]. In agreement with our present study, Klingenberg et al recently reported that subcutaneous immunization with HSP65 reduces atherosclerosis in $\mathrm{ApoE}^{-/-}$mice [25], but we used HSP60 peptide rather than HSP65 protein. One possible explanation could be that the HSP60 peptide incorporated in the dendroaspin scaffold may serve as a protein (HSP60)-like antigen through molecular mimicry. However, the mechanism of $\bigcirc$ HSP60/65 on lesion formation is still under investigation as other studies have reported increased fatty streak formation after immunization with HSP65 using a similar subcutaneous route of administration in mice [26,27].

Cytokines TNF- $\alpha$ and IFN- $\gamma$ activate other cells in the vasculature, thus orchestrating an inflammatory response to atherogenesis [28]. Based on the cytokine profiles from either sera or spleen cells in immunized mice, the TNF- $\alpha$ and IFN- $\gamma$ release may well be linked to the ability of the immune animals to release TNF- $\alpha$ and IFN- $\gamma$ from pre-primed cells, leading to a decrease in the need to synthesize significant amounts of new TNF- $\alpha$ and IFN- $\gamma$. Our results show that vaccination with any of the constructs containing inserts promoted a major shift away from pro-inflammatory cytokines (ie TNF- $\alpha$ and IFN- $\gamma$ ), towards anti-inflammatory cytokines (particularly IL-10 and TGF- $\beta$ ), that is evident not only in the plaque but systemically too. Although these results strongly suggest that this generalized anti-inflammatory response is responsible for the reduction in plaque size and inflammatory cell content observed, they do not discriminate the reduction is dependent on which antiinflammatory cytokine, as both IL-10 and TGF- $\beta$ were implicated to play a role in atherosclerosis $[29,30]$. A strategy using IL-10 or TGF- $\beta$ knock out mice will be required to delineate the relative contributions of these two cytokines. 
Our present study further demonstrates that both termini of the dendroaspin protein scaffold can be extended and that antigenic epitopes can be substituted into loop III to produce functional multipleepitope recombinant protein antigens. A higher immune response can be expected with more epitopes introduced into dendroaspin scaffold before probably reaching a saturated immune response. Our experiments do not exclude the possibility that other epitopes and other positions within the dendroaspin structure may be more beneficial in immunizing against atherosclerosis.

The discovery of Foxp3 as the key transcription factor controlling Treg cell development and function is one of the most significant advances in Treg immunobiology. The mechanism of reducing atherosclerotic lesion formation by immunization with these recombinant antigens is, at least in part, due to increasing Treg cell concentration in immunized mice, either locally (in the lesions) or in remote organs (splenocytes): we observed that concentrations of $\mathrm{CD}^{+}{ }^{+}$-expressing Treg cells were significantly higher in mice immunized with these recombinant constructs than in those of control mice immunized with GST-dendroaspin either locally (in lesion site of aorta) or in remote organs (splenocytes or lymphocytes). In addition, the atheroprotective effect paralleled an induction of Treg suppression of antigen-specific effector T-cells. This mechanism has been demonstrated in intranasal immunization [31] and subcutaneous immunization with ApoB peptide [32]. In agreement with our present findings, it appears that modulation in atherosclerosis-related autoimmunity by antigenspecific activation of Tregs represents a novel approach for the treatment of atherosclerosis.

Notably, our findings have demonstrated that the Cpn epitope in constructs AHHC and AHC contributed to lesion reduction in uninfected mice. Assuming the possibility that the mice are already infected with $C p n$, then the $C p n$ epitope is still capable of playing a role in lesion reduction. In a separate study we found that the $C p n$ peptide reduces lesion formation in the same mouse strain 
infected with Cpn (Xia et al unpublished data). Our preliminary results suggest that the Cpn epitope has the capacity to induce regulatory T-cells and contribute to prevention of early lesion formation by inducing an antigen-specific regulatory immune response (data not shown). Therefore, constructs AHHC and AHC containing a Cpn epitope may also be used to develop a vaccine against atherosclerosis in which Cpn infection plays an important role. Cpn protein, one of a variety of disease-related antigens, together with oxidized low-density lipoprotein and hHSP60 may stimulate $\mathrm{CD} 4^{+} \mathrm{T}$-cells in the context of atherogenesis [33]. Antigen-specific immunotherapy involves the use of inverse vaccination for a specific autoantigen such as ApoB and HSP or their specific epitopes. Application of antigen-specific immunotherapy has an attractive advantage of permitting selective inactivation of autoreactive T-cells without interfering with normal immune function [34]. Our findings have suggested that developing a protein-based vaccine using a dendroaspin scaffold may offer attractive opportunities for the development of multivalent vaccines against atherosclerosis.

\section{Supplementary material}

Supplementary material is available online.

\section{Acknowledgements}

We are indebted to Professor the Lord Kakkar for his continuous support; Professor Andras Miczak and Professor Katalin Burian for their technical advice, Dr Andrea Szabo for her technical assistance and Dr Mike Scully for invaluable discussion and Professors Anthony Dorling and Wolfrun Ruf for their review of the manuscript and helpful suggestions and Dr Sophie Rushton-Smith for editorial assistance. 


\section{Conflict of interest:}

None declared.

\section{Funding}

We gratefully acknowledge the support of the Trustees of the Thrombosis Research Institutes in London and in Bangalore, The Garfield Weston Foundation, UK, The Tata Social Welfare Trust, India (TSWT/IG/SNB/JP/SDM) and The Department of Biotechnology, Ministry of Science and Technology, Government of India (BT/01/COE/08/07). Valeria Endresz and Ildiko Faludi were also supported by a grant from Hungary (TÁMOP-4.2.1/B-09/KONV-2010-0005). The sponsors did not participate in the design, conduct, sample collection analysis or interpretation of the data, or in the preparation, review or approval of the manuscript. 


\section{References:}

1. Lu X, Chen D, Endresz V, Xia M, Faludi I, Burian K, Szabo A, Csanadi A, Miczak A, Gonczol E, Kakkar V. Immunization with a combination of ApoB and hHSP60 epitopes significantly reduces early atherosclerotic lesion in Apobtm2SgyLdlrtm1Her/J mice. Atherosclerosis 2010;212:472-80.

2. Zernecke A, Weber C. Chemokines in the vascular inflammatory response of atherosclerosis. Cardiovasc Res 2010;86:192-201.

3. Libby P. Inflammation in atherosclerosis. Nature 2002;420:868-74.

4. Chyu KY, Nilsson J, Shah PK. Immunization for atherosclerosis. Current Atherosclerosis Reports 2007;9:104-9.

5. Grundtman C, Wick G. The autoimmune concept of atherosclerosis. Curr Opin Lipidol 2011;22:327-34.

6. Gordon S, Clarke S, Greaves D, Doyle A. Molecular immunobiology of macrophages: Recent progress. Curr Opin Immunol 1995;7:24-33.

7. Schiopu A, Bengtsson J, Söderberg I, Janciauskiene S, Lindgren S, Ares MP, Shah PK, Carlsson R, Nilsson J, Fredrikson GN. Recombinant human antibodies against aldehyde-modified apolipoprotein B-100 peptide sequences inhibit atherosclerosis. Circulation 2004;110:2047-52.

8. Bason C, Corrocher R, Lunardi C, Puccetti P, Olivieri O, Girelli D, Navone R, Beri R, Millo E, Margonato A, Martinelli N, Puccetti A. Interaction of antibodies against cytomegalovirus with heat shock protein 60 in pathogenesis of atherosclerosis. Lancet 2003;362:1971-7.

9. Choi JI, Chung SW, Kang HS, Rhim BY, Park YM, Kim US, Kim SJ. Epitope mapping of Porphyromonas gingivalis heat-shock protein and human heat-shock protein in human atherosclerosis. J Dent Res 2004;83:936-40. 
10. Campbell LA, Campbell LA, O'Brien ER, Cappuccio AL, Kuo CC, Wang SP, Stewart D, Patton DL, Cummings PK, Grayston JT. Detection of Chlamydia pneumoniae TWAR in human coronary atherectomy tissues. J Infect Dis 1995;172:585-8.

11. Sette A, Vitiello A, Reherman B, Fowler P, Nayersina R, Kast WM, Melief CJ, Oseroff C, Yuan L, Ruppert J, Sidney J, del Guercio MF, Southwood S, Kubo RT, Chesnut RW, Grey HM, Chisari FV. The relationship between class I binding affinity and immunogenicity of potential cytotoxic $\mathrm{T}$ cell epitopes. J Immunol 1994;153:5586-92.

12. Kadri R, Bermudez-Fajardo A, Puolakkainen M, Stewart G, Oviedo-Orta E. Effect of immunisation with Chlamydia pneumoniae recombinant major outer membrane protein on atherosclerosis development. Heart 2010;96:e27.

13. Binz HK, Pluckthun A. Engineered proteins as specific binding reagents. Curr Opin Biotechnol 2005;16:459-69. Chang JW, Mechling DE, Bächinger HP, Burrows GG. Design, engineering, and production of human recombinant $\mathrm{T}$ cell receptor ligands derived from human leukocyte antigen DR2. J Biol Chem 2001;276:24170-6.

14. Sutcliffe MJ, Jaseja M, Hyde EI, Lu X, Williams JA. Three-dimensional structure of the RGDcontaining neurotoxin homologue dendroaspin. Nat Struct Biol 1994;1:802-7.

15. Herbin O, Ait-Oufella H, Yu W, Fredrikson GN, Aubier B, Perez N, Barateau V, Nilsson J, Tedgui A, Mallat Z. Regulatory T-cell response to apolipoprotein b100-derived peptides reduces the development and progression of atherosclerosis in mice. Arterioscler Thromb Vasc Biol. 2012;32:605-12.

16. Klingenberg R, Lebens M, Hermansson A, Fredrikson GN, Strodthoff D, Rudling M, Ketelhuth DF, Gerdes N, Holmgren J, Nilsson J, Hansson GK. Intranasal immunization with an 
apolipoprotein B-100 fusion protein induces antigen-specific regulatory $\mathrm{T}$ cells and reduces atherosclerosis. Arterioscler Thromb Vasc Biol. 2010;30:946-52.

17. Wang F, Lee E, Lowes MA, Haider AS, Fuentes-Duculan J, Abello MV, Chamian F, Cardinale I, Krueger JG. Prominent production of IL-20 by CD68+/CD11c+ myeloid-derived cells in psoriasis: Gene regulation and cellular effects. J Invest Dermatol 2006;126:1590-9.

18. Fredrikson GN, Schiopu A, Berglund G, Alm R, Shah PK, Nilsson J. Autoantibody against the amino acid sequence 661-680 in apo B-100 is associated with decreased carotid stenosis and cardiovascular events. Atherosclerosis 2007;194:e188-92.

19. van Puijvelde GH, van Es T, van Wanrooij EJ, Habets KL, de Vos P, van der Zee R, van Eden W, van Berkel TJ, Kuiper J. Induction of oral tolerance to HSP60 or an HSP60-peptide activates T cell regulation and reduces atherosclerosis. Arterioscler Thromb Vasc Biol 2007;27:2677-83.

20. Kohm AP, Fuller KG, Miller SD. Mimicking the way to autoimmunity: an evolving theory of sequence and structural homology. Trends Microbiol 2003;11:101-5.

21. Zhao R, Loftus DJ, Appella E, Collins EJ. Structural evidence of T-cell xeno-reactivity in the absence of molecular mimicry. J Exp Med 1999;189:359-70.

22. Bobryshev YV. Dendritic cells in atherosclerosis: current status of the problem and clinical relevance. Eur Heart J 2005;26:1700-4.

23. Cybulsky MI, Jongstra-Bilen J. Resident intimal dendritic cells and the initiation of atherosclerosis. Curr Opin Lipidol 2010;21:397-403.

24. Habets KL, van Puijvelde GH, van Duivenvoorde LM, et al. Vaccination using oxidized lowdensity lipoprotein-pulsed dendritic cells reduces atherosclerosis in LDL receptor-deficient mice. Cardiovasc Res 2010;85:622-30. 
25. Klingenberg R, Ketelhuth DF, Strodthoff D, Gregori S, Hansson GK. Subcutaneous immunization with heat shock protein-65 reduces atherosclerosis in Apoe-/- mice. Immunobiology 2012;217:540-7.

26. Afek A, George J, Gilburd B, Rauova L, Goldberg I, Kopolovic J, Harats D, Shoenfeld Y. Immunization of low-density lipoprotein receptor deficient (LDL-RD) mice with heat shock protein 65 (HSP-65) promotes early atherosclerosis. J Autoimmun 2000;14:115-21.

27. George J, Afek A, Gilburd B, Shoenfeld Y, Harats D. Cellular and humoral immune responses to heat shock protein 65 are both involved in promoting fatty-streak formation in LDL-receptor deficient mice. J Am Coll Cardiol 2001;38:900-5.

28. Zhou X, and Hansson GK. Detection of B cells and proinflammatory cytokines in atherosclerotic plaques of hypercholesterolaemic apolipoprotein E knockout mice. Scand J Immunol 1999;50:2530.

29. Pinderski Oslund LJ, Hedrick CC, Olvera T, Hagenbaugh A, Territo M, Berliner JA, Fyfe AI. Interleukin-10 blocks atherosclerotic events in vitro and in vivo. Arterioscler Thromb Vasc Biol1999;19:2847-53.

30. Robertson AK, Rudling M, Zhou X, Gorelik L, Flavell RA, Hansson GK. Disruption of TGF-beta signaling in T cells accelerates atherosclerosis. J Clin Invest 2003;112:1342-50.

31. Klingenberg R, Lebens M, Hermansson A, Fredrikson GN, Strodthoff D, Rudling M, Ketelhuth DF, Gerdes N, Holmgren J, Nilsson J, Hansson GK. Intranasal immunization with an apolipoprotein B-100 fusion protein induces antigen-specific regulatory $\mathrm{T}$ cells and reduces atherosclerosis. Arterioscler Thromb Vasc Biol. 2010;30:946-952.

32. Herbin O, Ait-Oufella H, Yu W, Fredrikson GN, Aubier B, Perez N, Barateau V, Nilsson J, Tedgui A, Mallat Z. Regulatory T-cell response to apolipoprotein B 100-derived peptides reduces the 
development and progression of atherosclerosis in mice. Arterioscler Thromb Vasc Biol. 2012;32:605-612.

33. Chang JW, Mechling DE, Bächinger HP, Burrows GG. Design, engineering, and production of human recombinant $\mathrm{T}$ cell receptor ligands derived from human leukocyte antigen DR2. J Biol Chem 2001;276:24170-6.

34. Paulson KE, Zhu S, Chen M, Nurmohamed S, Jongstra-Bilen J, Cybulsky MI Resident intimal dendritic cells accumulate lipid and contribute to the initiation of atherosclerosis. Circ Res 2010;106:383-90. 


\section{Figure legends}

Figure 1: Levels of constructed protein-induced $\mathrm{IgG}$ antibodies in the sera of $\mathrm{Apob}^{\mathrm{tm} 2 \mathrm{Sgy}} \mathrm{Ldlr}^{\mathrm{tm} 1 \mathrm{Her}} \mathrm{J}$ mice at 2 and 12 weeks after the first immunization and in controls (GST-dendroaspin(den)immunized mice). The mean optical densities (ODs) and SEM obtained from plasma samples of constructs A-, H-, AH-, AHC- and AHHC-immunized mice on ApoB peptide, hHSP60 ${ }_{153-163}$ and hHSP60 $303-312, C p n$ peptide-coated ELISA plates are shown. Dilution ratio: 1:100.

Figure 2: Detection and quantitation of the lesion areas in the aorta of $\mathrm{Apob}^{\mathrm{tm} 2 \mathrm{Sgy}} \mathrm{Ldlr} \mathrm{r}^{\mathrm{tm} 1 \mathrm{Her}} \mathrm{J}$ mice fed on a high-fat diet after immunization with constructs versus controls (GST-dendroaspin and Alum).

A: Photomicrograph of lesions observed in atherosclerotic aortas as analyzed with elastin/van Gieson staining. Bar $=250 \mu \mathrm{m}$.

B: Scatter plot showing mean of lesion area $\left(\mu \mathrm{m}^{2}\right)$ in the aortic sinus of mice immunized with constructs compared with those in control (GST-dendroaspin + Alum) $\left(\mathrm{N}=8\right.$ mice). ${ }^{*} P<0.05$; $* * P<0.01 ; * * * P<0.001$

C: Lesion area versus total area in the sections of the aortic sinus (\%) (ratio of plaque areas in $\mathrm{mm}^{2}$ versus total areas) $(\mathrm{N}=8$ mice $)$.

D: Percentage of reduction in lesion size in the aortic sinus (the reduction of control [GSTdendroaspin+Alum] group was set at zero).

Figure 3: Assessment of inflammation-associated cells in the lesions of $\mathrm{Apob}^{\mathrm{tm} 2 \mathrm{Sgy}} \mathrm{Ldlr}^{\mathrm{tm} 1 \mathrm{Her}} \mathrm{J}$ mice fed on a high-fat diet after immunization with constructs $\mathrm{A}, \mathrm{H}, \mathrm{AH}, \mathrm{AHC}$ and $\mathrm{AHHC}$. 
A: Photomicrographs showing immunohistochemical staining of CD68 (green) and CD11c (red) markers.

B: Scatter plot showing anti-CD68-stained area in lesion versus total lesion area (\%); Data are given as the mean of 8 mice. One-way analysis of variance, $\mathrm{R}^{2}=0.611$.

C: Scatter plot showing anti-CD11c-stained area in lesion versus total lesion area (\%); Data are given as the mean of 8 mice. One-way analysis of variance, $\mathrm{R}^{2}=0.584$.

D: $\mathrm{CD}^{+} 8^{+}$and $\mathrm{CD} 11 \mathrm{c}^{+}$co-localization; Data are given as mean $\pm \mathrm{SEM}$ (derived from Figures $3 \mathrm{~B}$ and $3 C)$.

E: Photomicrographs showing immunohistochemical staining of $\mathrm{CD}^{+}$T-cells (green) and Foxp3 ${ }^{+}$ Treg cells (red) (magnificent X8).

F: Scatter plot showing anti-Foxp3-stained area versus anti-CD4 ${ }^{+}$stained area in lesion $(\mathrm{N}=8$ mice). One-way analysis of variance, $\mathrm{R}^{2}=0.656$.

G: Assessment of Treg cells as fold increase for percentage of Foxp $3^{+}$area compared with controls.

H: Photomicrographs showing immunohistochemical staining of CD4 ${ }^{+}$T-cells (green) and Foxp $3^{+}$ Treg cells (red) in splenocytes (magnificent x16).

I: Scatter plot showing Foxp $3^{+}$cell expression levels in spleen $\mathrm{CD}^{+}$cells ( $\mathrm{N}=6$ mice). One-way analysis of variance, $\mathrm{R}^{2}=0.745$. Data are given as mean \pm SEM. 


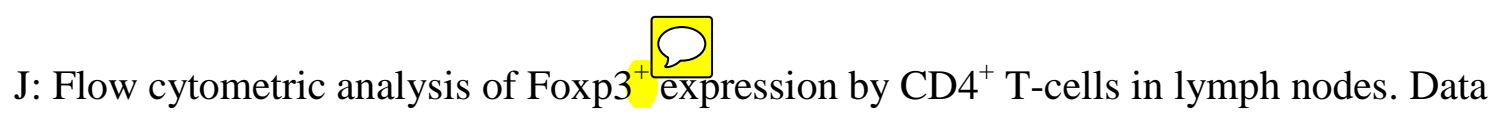
represent mean \pm SEM of data from three independent samples. $* P<0.05 ; * * * P<0.001$

Figure 4: Assessment of IL-10-producing T cells, TNF- $\alpha$ expression in the lesions and cytokine levels in $\mathrm{Apob}^{\mathrm{tm} 2 \mathrm{Sgy}} \mathrm{Ldlr}{ }^{\mathrm{tm} 1 \mathrm{Her}} \mathrm{J}$ mice fed a high-fat diet after immunization with constructs $\mathrm{A}, \mathrm{H}, \mathrm{AH}, \mathrm{AHC}$ and AHHC compared with controls.

A: Photomicrographs showing dual-immunohistochemical staining for IL-10 (red) and CD4 (green) (magnificent x8).

B: Scatter plot showing mean of IL-10-positive area co-localized with $\mathrm{CD}^{+}$area (\%) (N=8 mice). One-way analysis of variance, $\mathrm{R}^{2}=0.659$.

C: Photomicrographs showing dual-immunohistochemical staining of lesions in Apob ${ }^{\mathrm{tm} 2 \mathrm{Sgy}} \mathrm{Ldlr}^{\mathrm{tm} 1 \mathrm{Her}} \mathrm{J}$ mice fed a high-fat diet after immunization with constructs A, H, AH, AHC and AHHC for TNF- $\alpha$ (green).

D: Scatter plot showing mean of anti-TNF- $\alpha$ stained area in the lesion versus total lesion area $(\mathrm{N}=8$ mice). One-way analysis of variance, $\mathrm{R}^{2}=0.725$.

E-H: Cytokine levels measured in plasma.

I-L: Cytokine levels measured in the supernatant of splenocytes stimulated with ConA.

Data given as Mean of 6 analyses \pm SEM for E-L. $* P<0.05 ; * * P<0.01 ; * * * P<0.001$. 
Figure 5. Assessment of antigen-specific regulatory function. Splenic effector cells at $2 \times 10^{5}$ cells/well generated from either AHC-immunized mice or GST-immunized control mice. Proliferation of effector cells alone is indicated in the leftmost bar of each group. Addition of $\Omega$

isolated Treg cells from construct A- or H-immunized animals or KLH-immunized controls is indicated at different ratios to affect cells. Data are expressed as mean of 5 analyses \pm SEM. Differences between groups are shown; $P<0.05, P<0.01$ and $P<0.001$. 


\section{Figure 1}


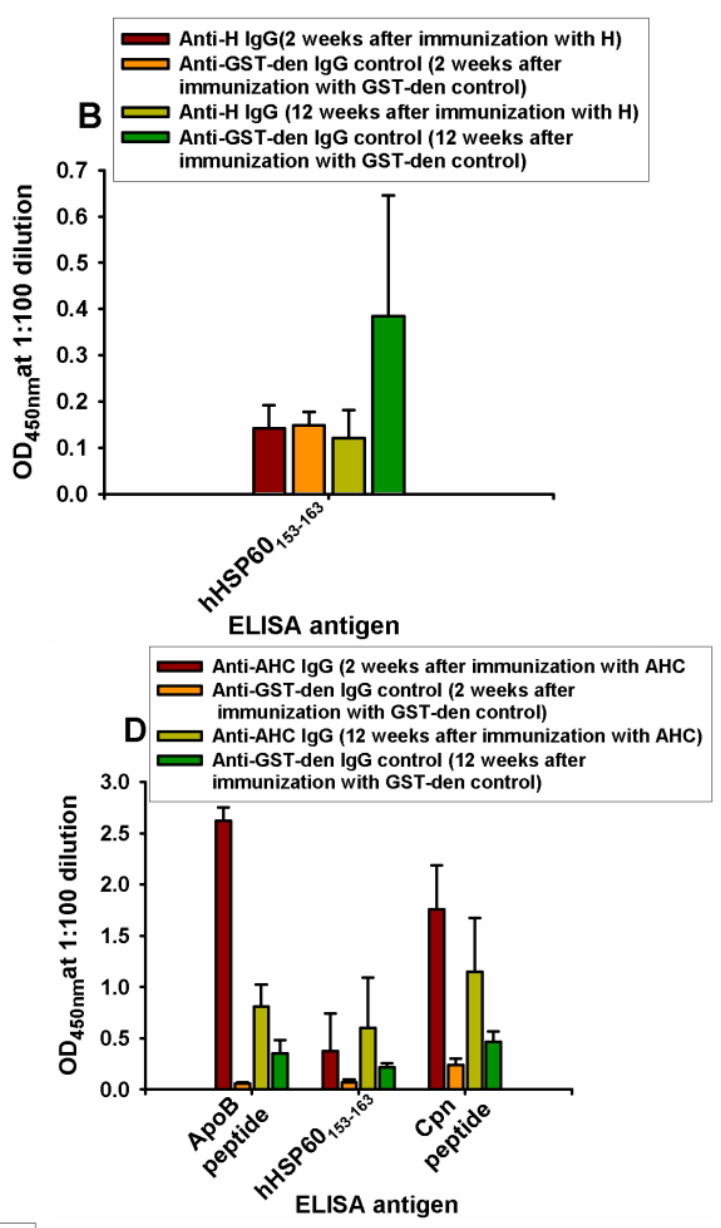

ELISA antigen 
Figure 2
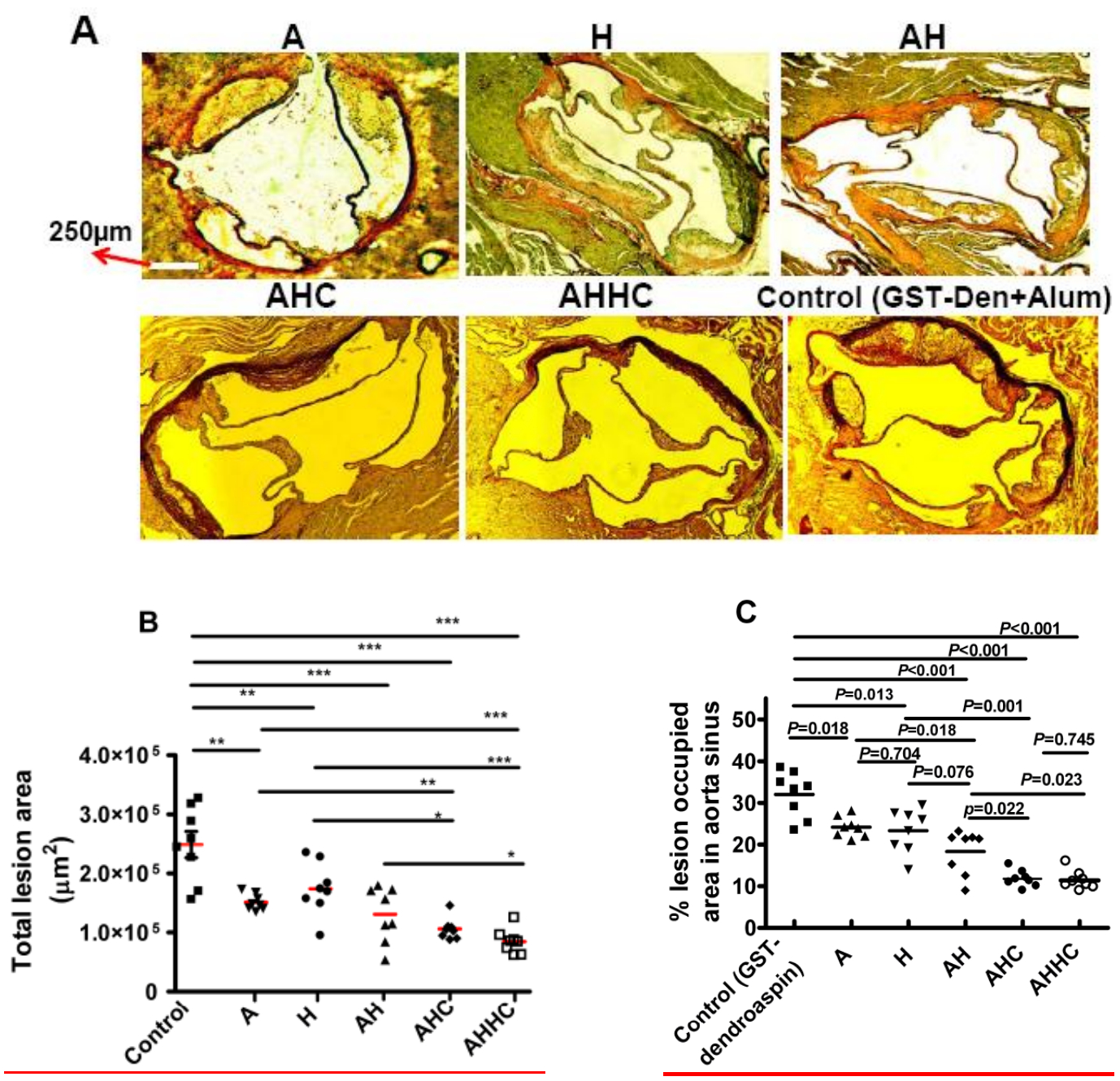

D

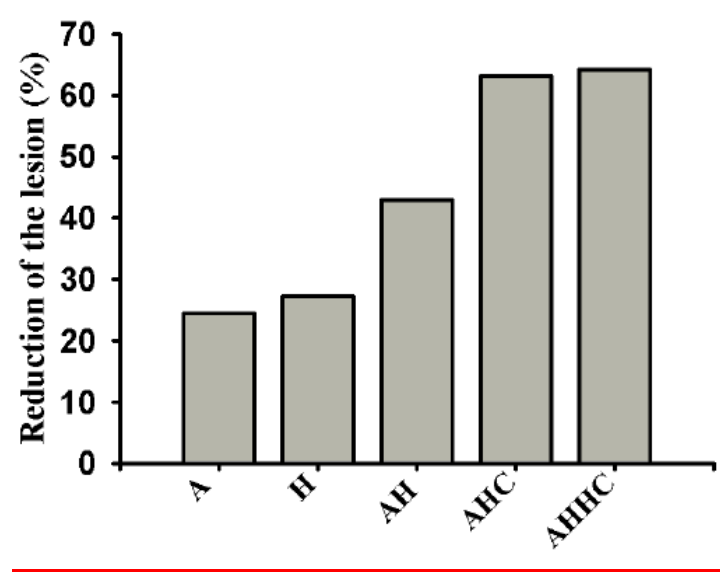


Figure 3

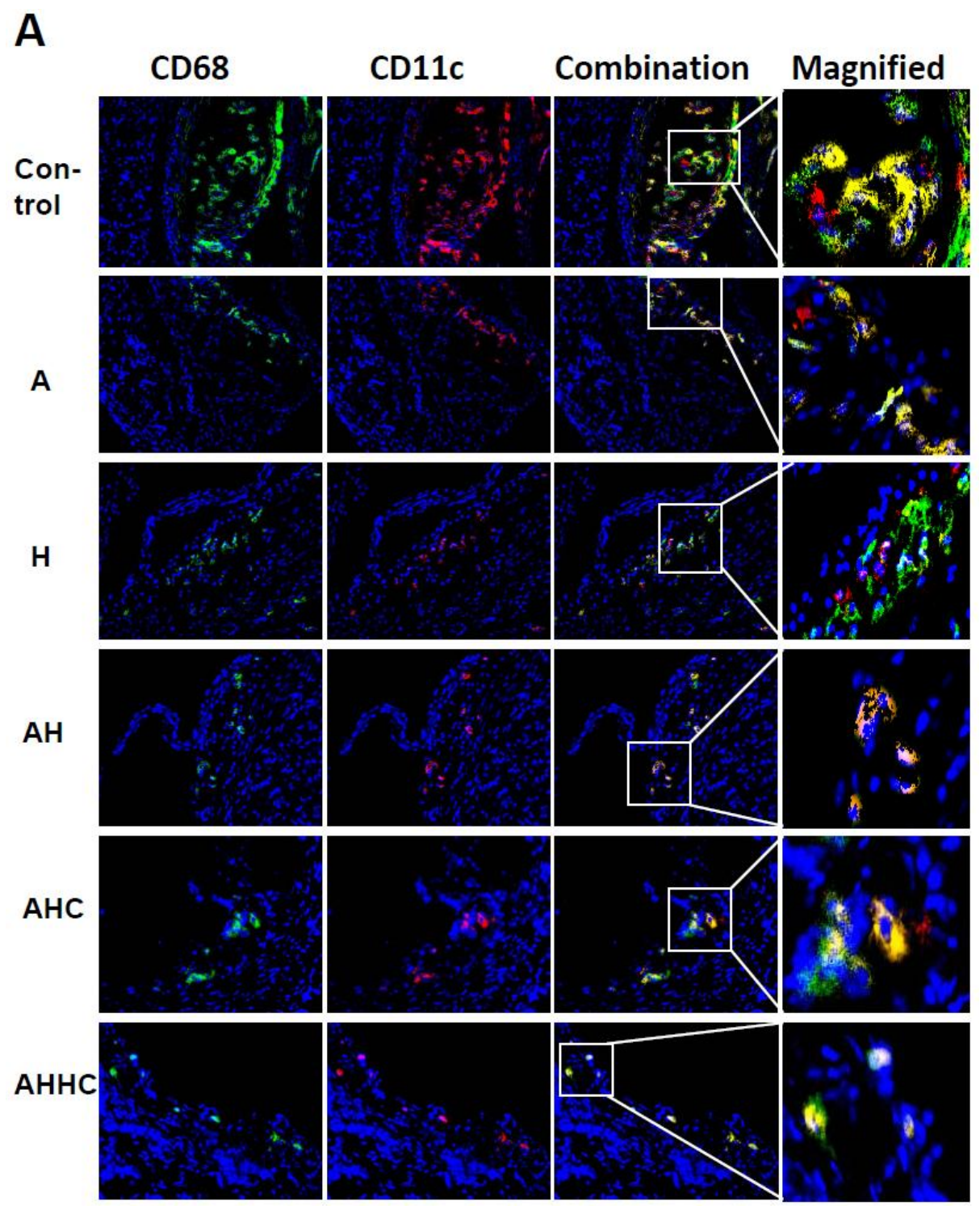



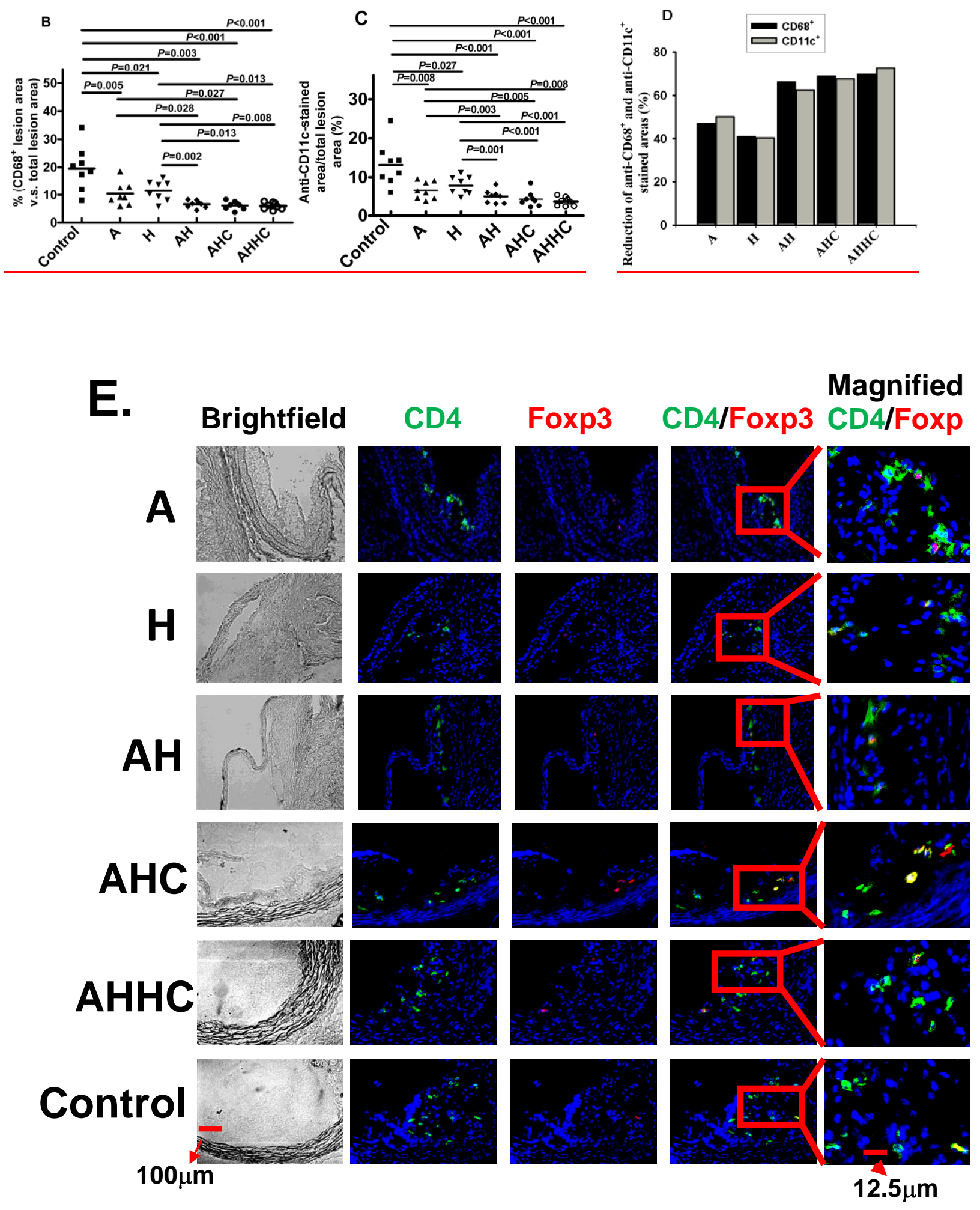

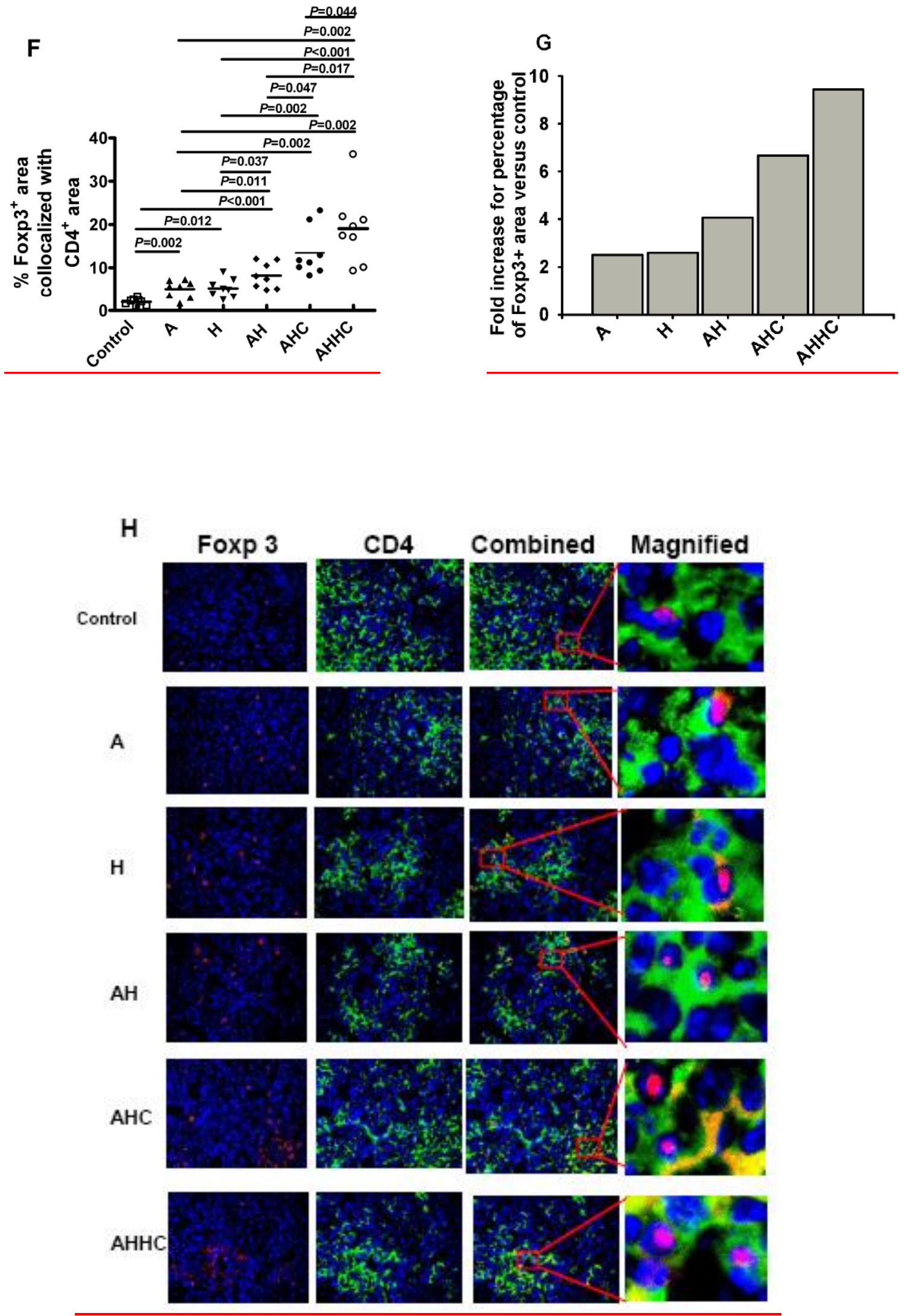


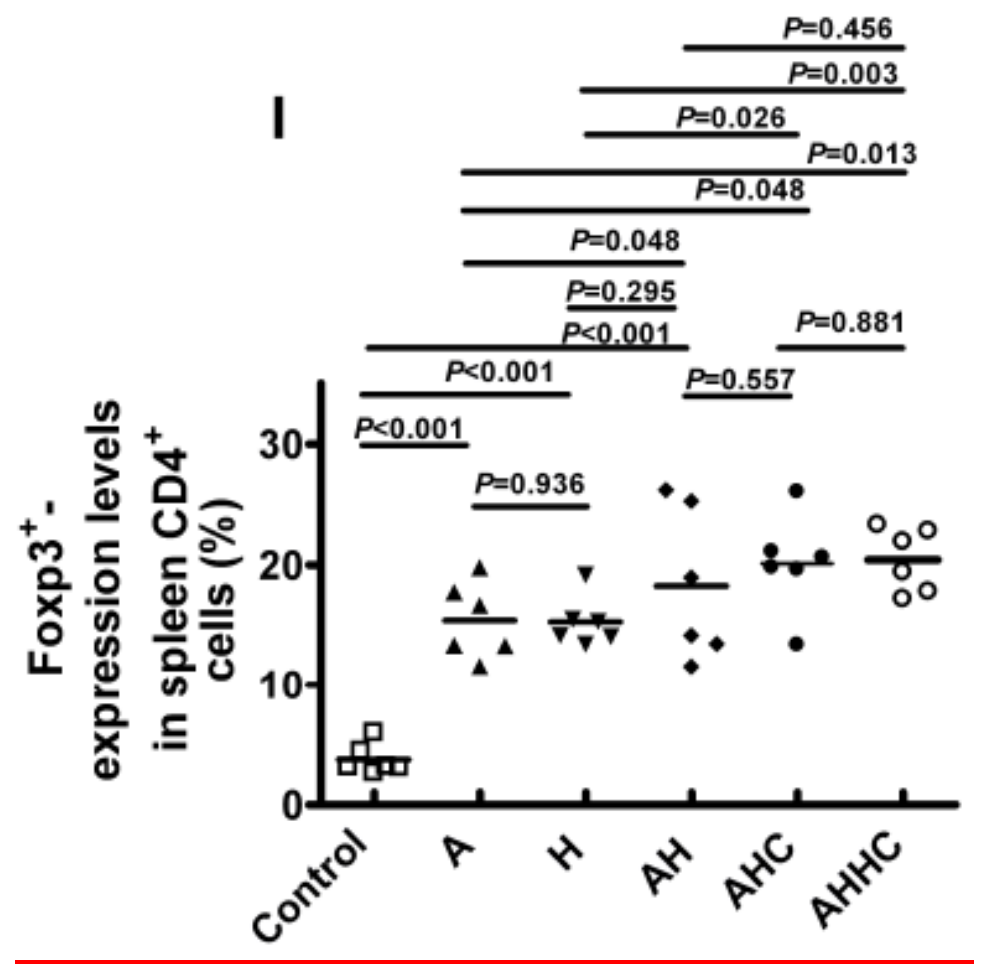




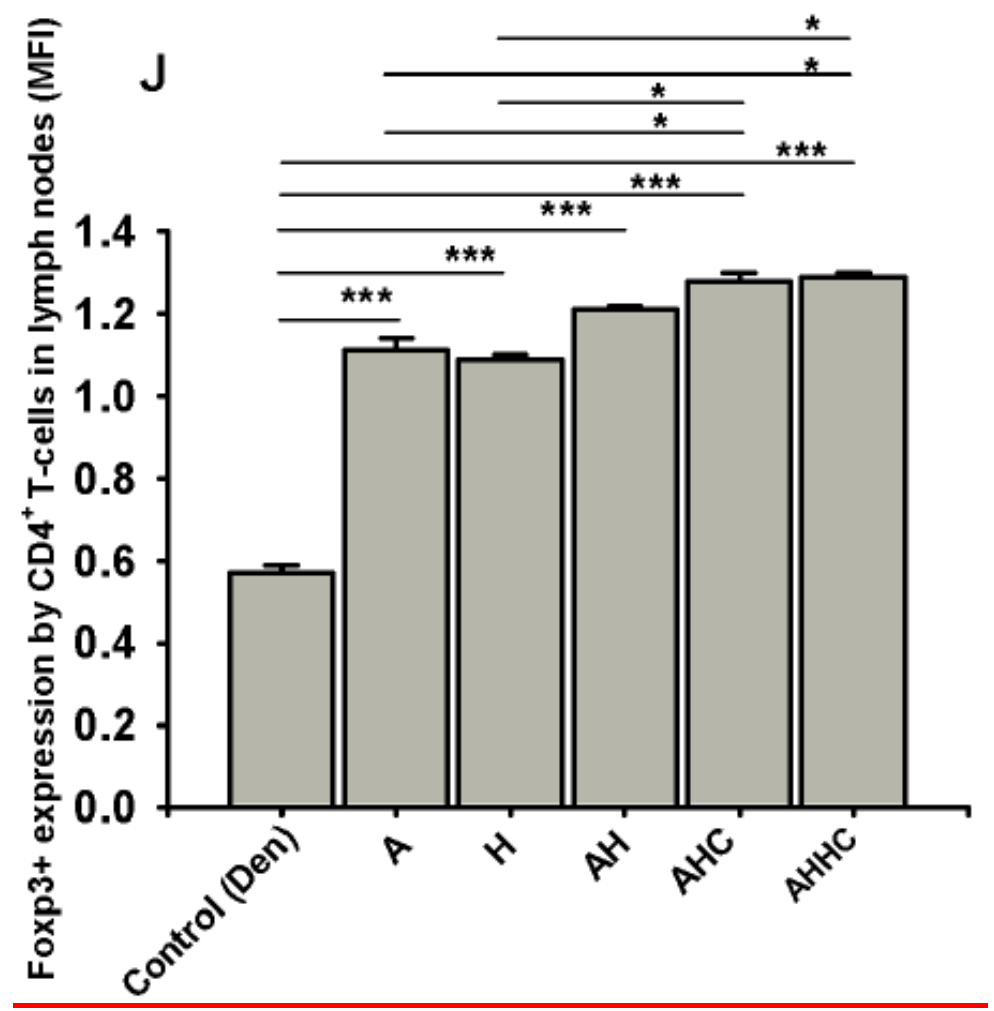


Figure 4
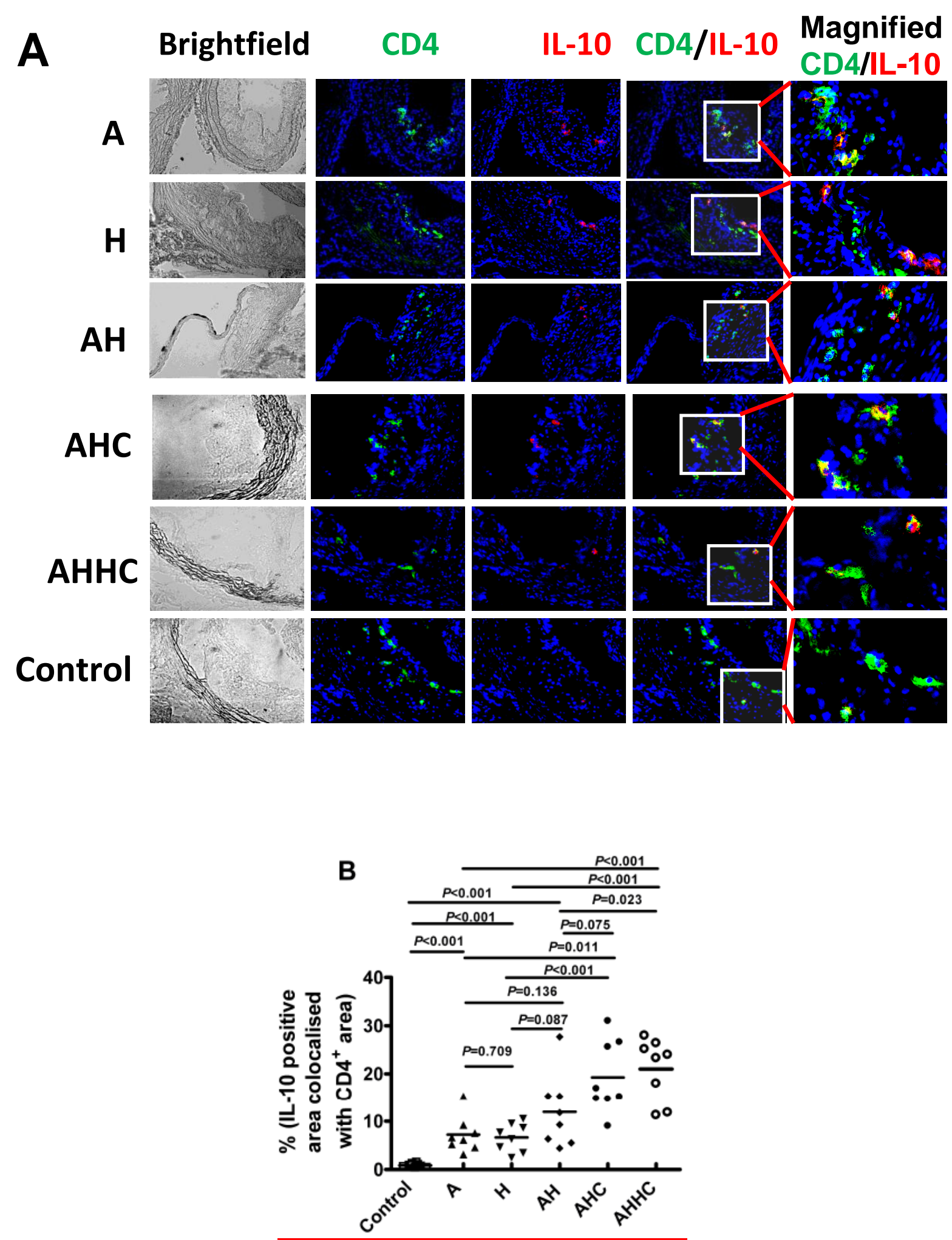


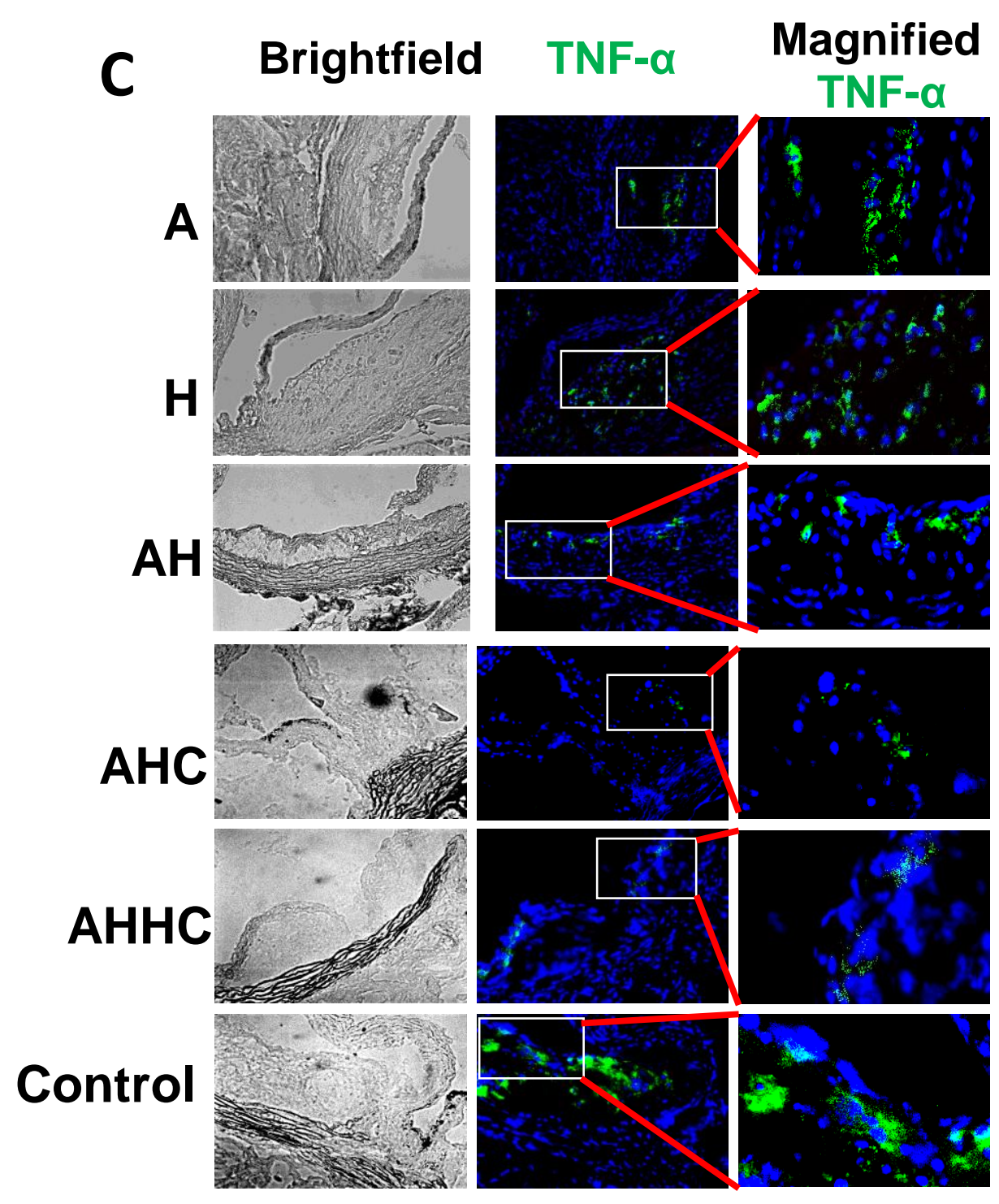





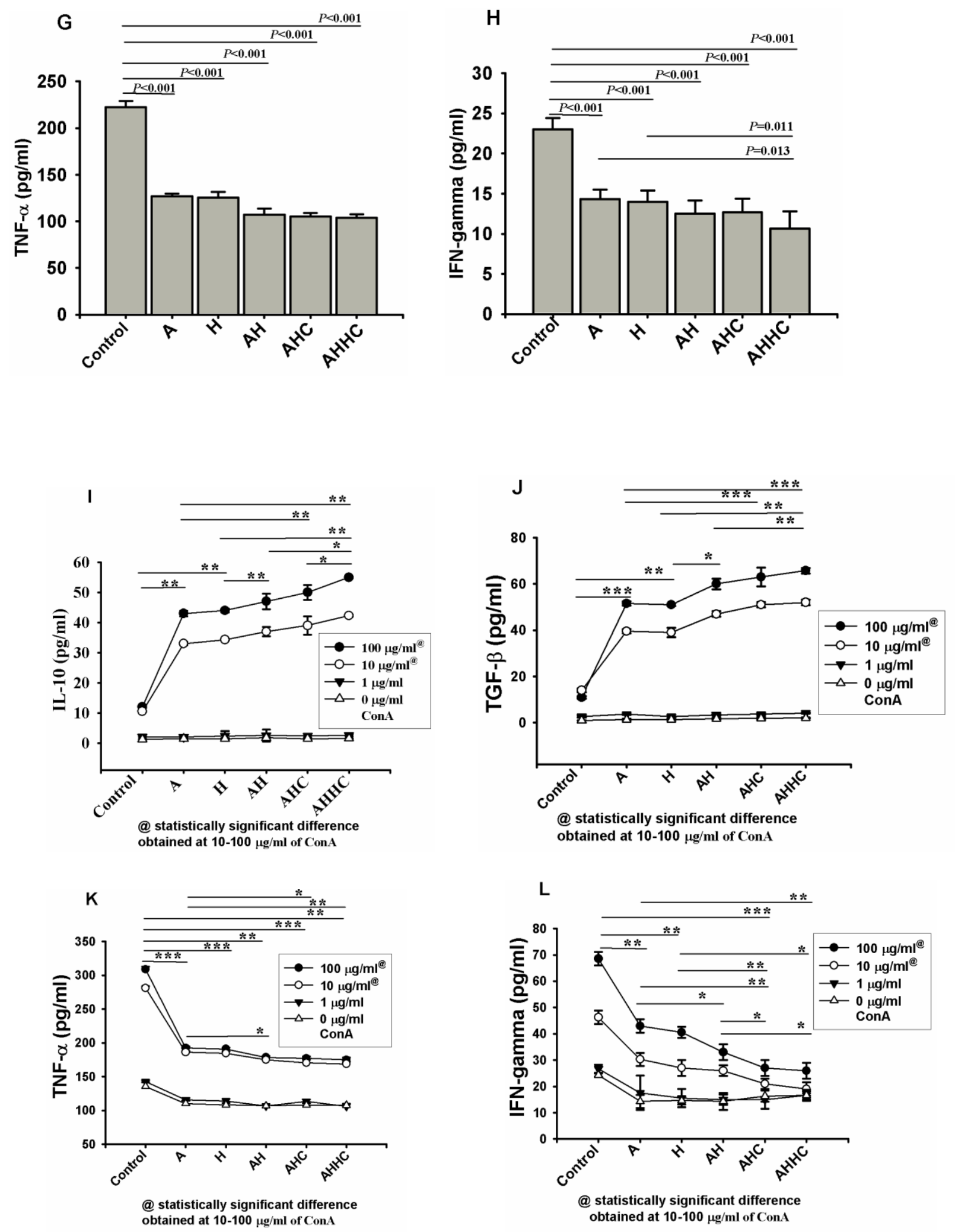

$* P<0.05 ; * * P<0.01 ; * * * P<0.001$. 


\section{Figure 5}

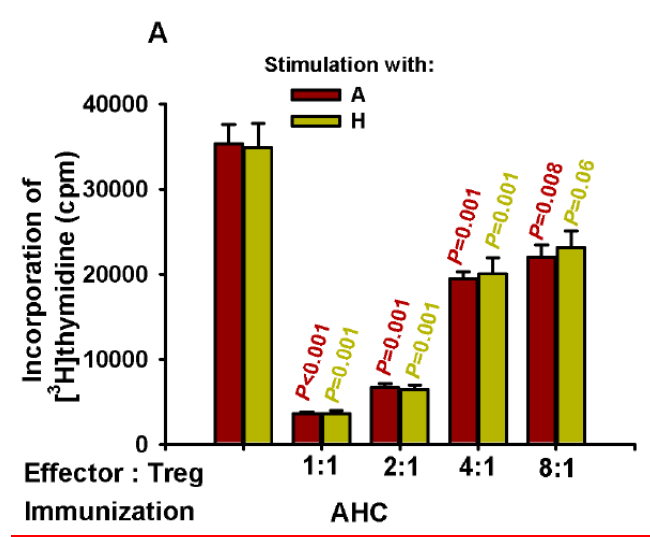

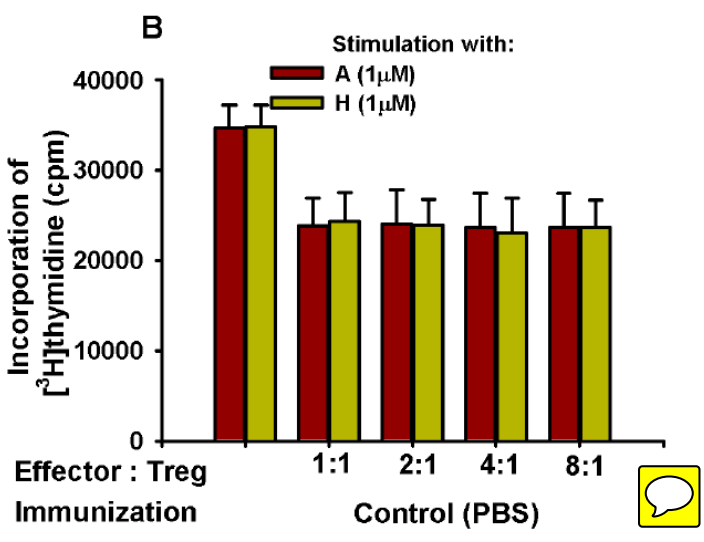

